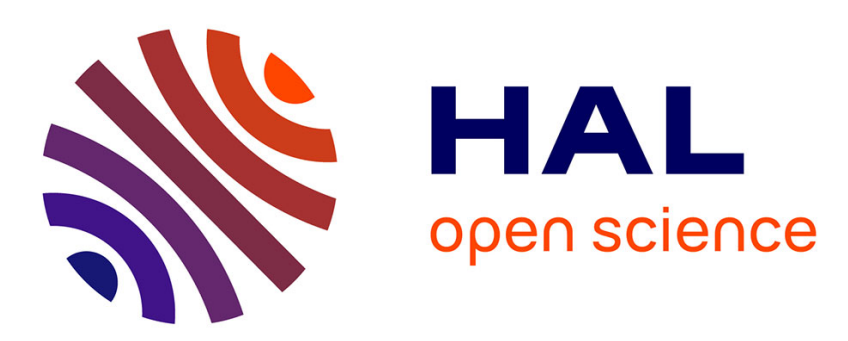

\title{
Toward the control of thickness and uniformity in the coating of TiO 2 -P25 on glass
}

Jihène Soufi, Miriam Pastor-Franco, Shuzhen Zhou, Reddad Hardala, Floriane Houillon, Valérie Meille, Dominique Richard

\section{- To cite this version:}

Jihène Soufi, Miriam Pastor-Franco, Shuzhen Zhou, Reddad Hardala, Floriane Houillon, et al.. Toward the control of thickness and uniformity in the coating of TiO 2 -P25 on glass. Particulate Science and Technology, 2015, 34 (2), pp.229 - 234. 10.1080/02726351.2015.1068898 . hal-01925602

\section{HAL Id: hal-01925602 https://univ-lyon1.hal.science/hal-01925602}

Submitted on 9 Apr 2019

HAL is a multi-disciplinary open access archive for the deposit and dissemination of scientific research documents, whether they are published or not. The documents may come from teaching and research institutions in France or abroad, or from public or private research centers.
L'archive ouverte pluridisciplinaire HAL, est destinée au dépôt et à la diffusion de documents scientifiques de niveau recherche, publiés ou non, émanant des établissements d'enseignement et de recherche français ou étrangers, des laboratoires publics ou privés. 


\title{
Towards the control of thickness and uniformity in the coating of $\mathrm{TiO}_{2}-\mathrm{P} 25$
}

\author{
on glass \\ Jihène Soufi, Miriam Pastor-Franco, Shuzhen Zhou, Reddad Hardala, \\ Floriane Houillon, Valérie Meille*, Dominique Richard
}

Université de Lyon, Institut de Chimie de Lyon, Laboratoire de Génie des Procédés Catalytiques, CNRS, CPE Lyon, 43 bd du 11 novembre 1918, BP 82077, 69616 Villeurbanne cedex, France

* Corresponding author, vme@1gpc.cpe.fr, tel: +33 (0)4 72431755 - Fax: +33 (0)4 72431673

The deposition of $\mathrm{TiO}_{2}-\mathrm{P} 25$ on Pyrex glass is studied in order to propose a procedure for obtaining uniform and adherent thin films with a controlled thickness in the range between fractions of micrometer to a few tens of micrometers. Different deposition methods such as spray-coating, dip-coating and drop-coating of liquid suspensions of $\mathrm{TiO}_{2}-\mathrm{P} 25$ powder are considered. The effect of pretreatment of the glass support, as well as post-deposition steps such as drying condition and thermal treatment are also reported. A basic glass pretreatment and an acidic $\mathrm{TiO}_{2}$ suspension are chosen for an optimized adherence of the film. Drop-coating, associated with a slow drying under $55 \%$ relative humidity and a high temperature thermal treatment is the method of choice to prepare coated glass slides in a large range of film thicknesses.

\section{Introduction}

$\mathrm{TiO}_{2}$ is the most studied photocatalyst for reasons widely reported by consensus: better performances (Herrmann 2005), easy availability, low cost. Among the different sources of this material (synthesis or commercial), the commercial Aeroxide P25, produced by Evonik, is often the preferred one because of its high photocatalytic activity (Thevenet et al. 2005; Gaya and Abdullah 2008; Guillard et al. 2002). The use of structured reactors in photocatalytic applications implies the need to deposit a layer of $\mathrm{TiO}_{2}$ on the structure, most of the time made of 
glass because of its transparency to UV light allowing the source of photons to be located at the back. Back illumination of the glass may be useful when the liquid to treat is not transparent to UV light (presence of dusts, suspended matter, dark solution...). A comparative study of liquid-side irradiation and back-side irradiation can be found in the work of Vezzoli et al. (2013).

In many published works, the $\mathrm{TiO}_{2}$ layer is directly synthesised on the glass from a titanium alkoxide sol to better adhere to the surface (Choi et al. 2006; Yun et al. 2004). The direct deposition of commercial P25 on glass has nevertheless been published by different research groups. Mills et al. (2006) prepared some P25-coated plates to study the photomineralization of soot. P25 was directly suspended in pure water, and the coated plates were only dried at moderate temperature $\left(70^{\circ} \mathrm{C}\right)$. However, the coated material was not used in a liquid flow and the adherence was not a key parameter. Dijkstra et al. (2001), also using only water as the suspending P25 medium, concluded that the coating method had to be improved because considerable wash out of the catalyst was observed during photocatalytic experiments in liquid medium. To increase the adherence of P25 on glass, several additives have been proposed, the use of titanium alkoxide sol-gel being one of them, leading to a hybrid mixture sol/powder (Natarajan et al. 2011). Arabatzis et al. (2002) used a suspension made of P25, acetylacetone, Triton X100 and water that was displayed on glass plates by the doctor-blade technique. Sometimes P25 was mixed with a sol-gel of silica to improve the adherence, with (Chen and Dionysiou 2008) or without (Carbonaro et al. 2013) the addition of a

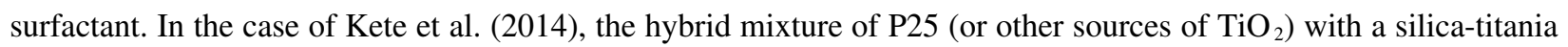
binder was found to be very resistant to scratch tests, despite the low-temperature treatment of the layer $\left(150^{\circ} \mathrm{C}\right)$. In our laboratory, a previous study was carried out to coat some $\mathrm{SiC}$ structured substrates with $\mathrm{TiO}_{2} \mathrm{P} 25$ ( $\mathrm{Rodriguez}$ et al. 2009). In the present work, the direct coating of this material on glass slides was studied. The objectives were to propose a simple method avoiding the use of organic additives and/or silica and providing uniform and adherent layers in a wide range of thicknesses. For that purpose, the influence of the glass pretreatment, suspension content, deposition method, drying conditions were evaluated.

\section{Experimental part}

\subsection{Material}

Evonik Aeroxide $\mathrm{TiO}_{2}$ (P25) was provided by Acros Organics. $\mathrm{NaOH}$, acetone, isopropanol, ethanol and deionised water were used for glass pretreatment tests. Triton X100, polyethylene glycol 200 (PEG), ethylene glycol (EG), 
acetylacetone (AA), ammonium polymethacrylate (Darvan $\mathrm{C}$ ) and hydrochloric acid $\mathrm{HCl}$ were used as additives to the $\mathrm{TiO}_{2}$ suspension. Pyrex glass slides $(26 \mathrm{~mm} \times 76 \mathrm{~mm} \times 1.1 \mathrm{~mm})$ were chosen as substrate because this material is mostly transparent to UV light for wavelength above $320 \mathrm{~nm}$ (extinction coefficient $\approx 0.52 \mathrm{~cm}^{-1}$ from de Lasa et al. (2005)).

\subsection{Analytical methods}

Contact angle measurements were performed with a Kruss drop shape analyzer - DSA30. The sessile drop method was used for measurement.

A Dektak 150 (Veeco Instruments Inc.) profilometer was used to determine the thickness and roughness of the coated catalyst films. Before profilometry examination, a line was carefully scratched on the coated glass slides by a knife to show the surface of the glass support. The course of the diamond stylus was set to run orthogonally to the scratch line. The thickness of the catalyst film coated was obtained by the average height difference between the surface of coated catalyst layer and the surface of the glass support (revealed by scratching). The adherence of the $\mathrm{TiO}_{2}$ layer was estimated by measuring the weight loss after 1 minute in heptane in an ultrasonic bath at room temperature ( $\mathrm{RT} \approx 20^{\circ} \mathrm{C}$ ) according to Meille et al. (2005). A qualitative result of the adherence test is provided ("+": adherence $>80 \%$, “-": adherence $<80 \%$ ). An adherence $>80 \%$ was indeed found sufficient to ensure a stability of the $\mathrm{TiO}_{2}$ layer during one day of photocatalytic experiments $(\mathrm{Re} \leq 800)$.

\subsection{Coating procedures}

\subsubsection{Preliminary steps}

Different glass pretreatments and additives in the $\mathrm{TiO}_{2}$ suspension were tested to get the highest adherence of the $\mathrm{TiO}_{2}$ layer on the glass.

\section{Glass pretreatment}

The pretreatments consist in immersing the glass slides in a solvent during 30 minutes, either at RT in an ultrasonic bath or at a given temperature in a thermostated bath. The solvents tested were: acetone, ethanol, i-propanol and the temperature ranged from 20 to $45^{\circ} \mathrm{C}$. Then, the plates were simply dried at room temperature after the organic pretreatments. In the case of basic pretreatments $(\mathrm{NaOH})$, the glass slides were further rinsed with deionized water 
and dried under air or $\mathrm{N}_{2}$ using a temperature program with a ramp rising from $20^{\circ} \mathrm{C}$ to $500^{\circ} \mathrm{C}$ in 2 hours, a plateau at $500^{\circ} \mathrm{C}$ for 4 hours and a decrease to $100^{\circ} \mathrm{C}$. Once removed from the oven at $100^{\circ} \mathrm{C}$, they were weighed immediately. The objectives of this temperature program were to get the glass slide tare under controlled conditions (very clean and dry glass surface) required for accurately weighing small amounts of $\mathrm{TiO}_{2}$ (few mg).

\section{Preparation of the suspension}

The suspensions were prepared by mixing $\mathrm{TiO}_{2}$, deionised water and the chosen additive (among those listed in paragraph 2.1) in an ultrasonic bath during 30 minutes. The $\mathrm{TiO}_{2}$ concentration was in the range [1.5-75 g/L]. The particle size distribution in the suspension has been measured by Rodriguez et al. (2009). It is in the range [1-15 $\mu \mathrm{m}]$. Note that the $\mathrm{TiO}_{2}$ concentration is very low, leading to suspension viscosities of the same order of magnitude as that of water.

\subsubsection{Coating methods}

Three coating methods were compared in terms of uniformity and range of thicknesses achieved.

\section{Spray-coating}

The spray-coating of the suspension was performed through a Sono-Tek microspray ultrasonic nozzle (10kHz). Three factors were studied: the $\mathrm{TiO}_{2}$ concentration, the scanning speed of the nozzle and its distance to the glass support.

\section{Dip-coating}

The glass substrates were dipped into the prepared $\mathrm{TiO}_{2}$ suspension for 5 seconds, withdrawn slowly (ca. $\left.1 \mathrm{~cm} / \mathrm{s}\right)$ and shaken to remove the excess of suspension. After that, one face of the coated glass slides was cleaned immediately to make sure that no $\mathrm{TiO}_{2}$ remained.

\section{Drop-coating}

Drop-coating method was performed by pouring a controlled volume of suspension on the surface of the glass plate, set horizontally, using a plastic liquid dropper with suction bulb. 


\subsubsection{Post-treatment of the films}

The post-treatment aims at obtaining adherent solid films without cracks. It involves two steps: a drying of the liquid film and a further thermal treatment of the solid deposit.

\section{Drying}

Once deposited, the films were first dried at room temperature. Different drying atmospheres at controlled humidity were obtained by using saturated salt solutions of $\mathrm{NaCl}, \mathrm{Mg}\left(\mathrm{NO}_{3}\right)_{2}$ and $\mathrm{MgCl}_{2}$. The drying duration was from a few hours to several days, depending on the liquid film thickness and the relative humidity.

\section{Thermal treatment}

After drying, a thermal treatment step was performed under $\mathrm{N}_{2}$ using a temperature program with a ramp rising from $20^{\circ} \mathrm{C}$ to $500^{\circ} \mathrm{C}$ in 2 hours, a plateau at $500^{\circ} \mathrm{C}$ for 4 hours and a decrease to $100^{\circ} \mathrm{C}$. The aim of the thermal treatment was to remove the additives and to make the film adhere to the surface. Attempts to perform a thermal treatment at a lower temperature $\left(350^{\circ} \mathrm{C}\right)$ resulted in a bad adherence of the layer. The coated glass slides were weighted just at the exit of the oven at $100^{\circ} \mathrm{C}$, to avoid water adsorption.

\section{Results and discussion}

\subsection{Preliminary steps}

\subsubsection{Effect of the glass pretreatment}

[Table 1 about here]

Different chemical treatments of the glass slides were tested (Table 1). The influence of the glass pre-treatment on the uniformity and adherence of the $\mathrm{TiO}_{2}$ layer was recorded. Contact angle measurements were also performed to characterize the spreading of the suspension on the glass surface. Only one suspension was selected for those measurements (Table 1). All the attempts with organic pre-treatment alone (i-propanol or acetone at $\mathrm{RT}$ or at $45^{\circ} \mathrm{C}$, ethanol at RT) led to non-adherent layers, even if the spreading was satisfactory (contact angle of $40^{\circ}$ with ethanol). 
On the contrary, the basic pretreatment $(\mathrm{NaOH} 1 \mathrm{M})$ at $90^{\circ} \mathrm{C}$ for 30 minutes gave some adherent layers, even with high contact angles of $85^{\circ}$.

\subsubsection{Effect of additives in the suspension}

The role of additives was expanded from the non successful test of sodium hexametaphosphate performed in the publication of Rodriguez et al. (2009). Amongst many organic additives tested, Triton X100, PEG, EG and AA gave a worse adherence of the $\mathrm{TiO}_{2}$ layer than water alone (Table 1). On the contrary, Darvan $\mathrm{C}$ led to an increased adherence. The same improvement was also obtained with an acidification of the suspension by $\mathrm{HCl} 1 \mathrm{M}$. In the latter case, the adherence on $\mathrm{NaOH}$-treated plates was probably due to an acid-base interaction between the liquid and the surface. To avoid the presence of organic residues, the use of the acidified suspension was preferred.

In the next paragraphs, the procedure retained and used for all the experiments includes the following steps:

- $\quad$ the glass plates are first degreased 30 minutes in acetone in an ultra-sonic bath, then treated at $90^{\circ} \mathrm{C}$ for 30 minutes in $\mathrm{NaOH} 1 \mathrm{M}$, rinsed and dried an aqueous suspension made of $\mathrm{TiO}_{2}(1.5$ to $75 \mathrm{~g} / \mathrm{L})$ in diluted hydrochloric acid ( $\mathrm{pH} 2$ to 3 ) is applied to the plates by the different coating methods described in section 3.2.

\subsection{Effect of the deposition method}

\subsubsection{Spray-coating}

Several glass plates have been spray-coated with three different suspensions $(2.5,7.5$ and $15 \mathrm{~g} / \mathrm{L})$ at different spraying heights and different scanning speeds of the nozzle (in one single pass). Spray-coating allows to obtain thin layers but with a rather bad homogeneity of the film. The $\mathrm{NaOH}$ pretreatment leads to a bad spreading of the suspension on the surface. Then, a partial drying during spraying leading to isolated spots instead of a continuous film is sometimes encountered, depending on the temperature in the room. Thus, the spray doesn't result in an uniform film but rather to the juxtaposition of spots, which can eventually coalesce depending on the amount of the suspension and the drying conditions (see example in Figure 1).

[Figure 1 about here] 
Two different models were used to try to predict the mass of $\mathrm{TiO}_{2}$ of the coating from the shape of the spray, the distance nozzle-slide and the operating conditions, such as the flow through the nozzle (Q) and the scanning speed (v) (Figure 2).

[Figure 2 about here]

Assuming an uniform deposition of the suspension on the slides (of surface area $\mathrm{a}=19.7 \mathrm{~cm}^{2}$ ) during the spraying, the mass of $\mathrm{TiO}_{2}$ deposited can be derived for a conic spray with equation:

$$
m=\frac{Q a}{v} \cdot \frac{2}{h \tan \theta} C_{\mathrm{TiO}_{2}}
$$

and for a parabolic one with:

$$
m=\frac{Q a}{v} \cdot \frac{1}{\pi p \sqrt{h}} C_{\mathrm{TiO}_{2}}
$$

The use of these relations requires the preliminary determination of: a) the suspension flow rate, for each concentration of $\mathrm{TiO}_{2}$ in the suspension, and b) the diameter of the sprayed area for different height of the nozzle above the glass slide for each concentration of $\mathrm{TiO}_{2}$ which leads to the parameters $\tan \theta$ for the conic model and $p$ for the parabolic model. The best model describing the effect of the concentration of $\mathrm{TiO}_{2}$ in the suspension $(2.5-15$ $\mathrm{g} / \mathrm{L}$ ), the scanning speed of the nozzle (range $5-25 \mathrm{~mm} \cdot \mathrm{s}^{-1}$ ) and the distance between the glass plate and the nozzle (25-55 mm) was the parabolic one (Figure 3).

[Figure 3 about here]

\subsubsection{Dip-coating}

[Figure 4 about here]

Suspensions from 2.5 to $30 \mathrm{~g}_{\mathrm{TiO} 2} / \mathrm{L}$ have been applied on glass plates by dip-coating. Due to the high contact angle between the suspension and the glass surface, an uniform liquid film was not formed and the Landau-Levich-Derjaguin equation from de Ryck and Quéré (1998) was not applicable. After drying, rinsing one side of the plate and thermal treatment, the mass obtained was found to increase slightly with the suspension concentration (Figure 4). The restricted variability of the mass and the very bad uniformity of the layer were found crippling for the use of that method (See photo inserted on Figure 4). 


\subsubsection{Drop-coating}

The advantage of this method is that the mass of $\mathrm{TiO}_{2}$ can be precisely predicted since the volume of suspension dropped on the glass slide set horizontally, and its $\mathrm{TiO}_{2}$ concentration are known. The mass obtained can vary in a wide range depending on the volume spread over the slide surface (from a few drops to a few milliliters) and the concentration of $\mathrm{TiO}_{2}$ in the suspension:

$$
m=C_{\mathrm{TiO}_{2}} V
$$

A $\mathrm{TiO}_{2}$ mass in the range [0.2-100 mg] was obtained. An illustration of the method and the resulting liquid film (before drying) is presented in Figure 5.

[Figure 5 about here]

\subsection{Comparison of methods}

\subsubsection{Successive coatings}

[Figure 6 about here]

Successive coatings have also been studied as a way to increase the $\mathrm{TiO}_{2}$ mass on the plate (Figure 6). Attempts to simply treat the intermediate layers at $120^{\circ} \mathrm{C}$ led to less adherent layers (not presented). A thermal treatment at $500^{\circ} \mathrm{C}$ was necessary between each layer. Thus, despite the possibility to reach thick layers by successive coatings with dip- spray- or drop-coating, they were more easily and rapidly obtained by the drop-coating method, and the film was more uniform. The result of drop-coating may look similar to that of the doctor-blade technique, the former method being based on a self-leveling coating (non-viscous suspension), the latter depending on the leveling of the doctor-blade (Berni et al. 2004; Ngamsinlapasathian et al. 2006). The advantage of drop-coating vs. doctor-blade is that the exact amount of slurry deposited (and thus of $\mathrm{TiO}_{2}$ ) is known. 


\subsubsection{Density of $\mathrm{TiO}_{2}$}

The mass of $\mathrm{TiO}_{2}$ coated on the glass slides has been plotted vs. the thickness measured by profilometry for the different coating methods (Figure 7). A common linear tendency was found with a slope corresponding to a density of the coating of $1.64 \pm 0.04 \mathrm{~g} . \mathrm{cm}^{-3}$.

[Figure 7 about here]

This value is in good agreement with published values for $\mathrm{TiO}_{2}-\mathrm{P} 25$ films (2 $\mathrm{g} . \mathrm{cm}^{-3}$ from Baranova et al. (2007), $1.49{\mathrm{~g} . \mathrm{cm}^{-3}}^{-3}$ calculated from Zhao et al. (2012)). It is far from the bed density of P25 powder $\left(0.13 \mathrm{~g} . \mathrm{cm}^{-3}\right)$ because of compaction of particles during coating but not far from the density of ideal compactness, $1.95{\mathrm{~g} . \mathrm{cm}^{-3}}^{-3}$, calculated from the crystal density of P25 $\left(3.9 \mathrm{~g} . \mathrm{cm}^{-3}\right)$ and the mesopore volume of the P25 powder $\left(0.25 \mathrm{~g} . \mathrm{cm}^{-3}\right)$, leading to a porosity of 0.5 (Porosity = mesopore volume/(mesopore volume $+1 /$ crystal density) from Zhao et al. (2012)). The difference is likely due to the stacking (intergranular) porosity, which seems to be similar whatever the coating method. This similarity is not surprising since the suspension used and the drying/thermal treatment procedures are the same whatever the deposition method used.

\subsection{Effect of the drying conditions}

It is known that a slow drying avoids the formation of cracks and favours an uniform surface (Fabes et al. 1986). Therefore, different drying conditions at $20^{\circ} \mathrm{C}$ were tested to determine the appropriate humidity conditions to get a dry plate with an uniform coating. The influence of drying is maximised in the case of drop-coating since the amount of liquid deposited on the glass is higher. It was found that a drying at low humidity conditions $\left(\mathrm{MgCl}_{2}, 33 \% \mathrm{RH}\right.$ from Greenspan (1977)) was rapid and led to a non-uniform film with many waves (Figure 8, left). On the contrary, a drying in more humid atmospheres $\left(\mathrm{Mg}\left(\mathrm{NO}_{3}\right)_{2}, 55 \% \mathrm{RH}\right)$ or $\left.\mathrm{NaCl}, 75 \% \mathrm{RH}\right)$ led to uniform films (Figure 8, right).

The RH provided by the use of $\mathrm{Mg}\left(\mathrm{NO}_{3}\right)_{2}$ was considered as a good compromise between uniformity and drying duration. However, adherence tests showed a high adherence of the solid film on the surface (> $80 \%)$, whatever the drying method.

[Figure 8 about here]

SEM pictures of the $\mathrm{TiO}_{2}$ layer obtained by the different drying media are shown in Figure 9. It was confirmed that drying at intermediate relative humidity provides a more uniform layer, with limited cracks. 
[Figure 9 about here]

A good uniformity was also obtained by letting the plates dry slowly in the fridge (not shown), the key point being to avoid a fast drying. Several days were required to achieve the drying before the thermal treatment.

\section{Conclusion}

The coating of glass slides was carried out by different methods using an aqueous suspension of $\mathrm{TiO}_{2}-\mathrm{P} 25$ powder. To get a high adherence of the $\mathrm{TiO}_{2}$ on the glass, a basic pretreatment of the surface, combined to the use of an acidic suspension were necessary. This combination was not favorable to spraying or to dip-coating, because of a high contact angle liquid/surface. In contrast, the drop-coating method was well-adapted to obtain an uniform film layer. A slow drying under wet conditions $(55 \% \mathrm{RH})$ was the key to get an uniform solid film. After thermal treatment, all the coated plates, in the thickness range $[0.03-40 \mu \mathrm{m}]$, showed a similar solid film density of 1.64 g. $\mathrm{cm}^{-3}$. The thickness was thus easily predictable thanks to the volume dropped and the concentration of the suspension. In a further work, the slides with deposited $\mathrm{TiO}_{2}$ will be tested in a photocatalytic reaction in order to study the effect of the $\mathrm{TiO}_{2}$ thickness on the photocatalytic activity.

\section{Nomenclature}

a surface area of the slide $\left(\mathrm{m}^{2}\right)$

$\mathrm{C}_{\mathrm{TiO} 2}$ concentration of $\mathrm{TiO}_{2}$ in the suspension $\left(\mathrm{kg} / \mathrm{m}^{3}\right)$

$\mathbf{h}$ height of the nozzle above the glass slide $(\mathrm{m})$

m mass of $\mathrm{TiO}_{2}$ deposited on a single slide $(\mathrm{kg})$

p parameter for the spraying parabola $\left(\mathrm{m}^{1 / 2}\right)$

Q flow rate of the suspension through the nozzle $\left(\mathrm{m}^{3} \cdot \mathrm{s}^{-1}\right)$

$\mathbf{r}$ radius of the sprayed discus $(\mathrm{m})$

V Volume of suspension deposited by coating $\left(\mathrm{m}^{3}\right)$

$\mathbf{v}$ scanning rate of the nozzle or withdrawal rate from a suspension $\left(\mathrm{m} \cdot \mathrm{s}^{-1}\right)$

$\boldsymbol{\theta}$ half angle of the spraying cone 


\section{References}

Arabatzis, I. M., S. Antonaraki, T. Stergiopoulos, A. Hiskia, E. Papaconstantinou, M. C. Bernard, and P. Falaras. 2002. Preparation, characterization and photocatalytic activity of nanocrystalline thin film $\mathrm{TiO}_{2}$ catalysts towards 3,5-dichlorophenol degradation. J. Photochem. Photobiol., A 149, 237-245.

Baranova, E. A., G. Foti, H. Jotterand, and C. Comninellis. 2007. Electrochemical modification of the catalytic activity of $\mathrm{TiO}_{2} / \mathrm{YSZ}$ supported rhodium films. Topics in Catalysis 44(3), 355-360.

Berni, A., M. Mennig, and H. Schmidt. 2004. Doctor blade. In Sol-Gel Technologies for Glass Producers and Users ed. by M. A. Aegerter and M. Mennig, pp. 89-92. Springer US.

Carbonaro, S., M. N. Sugihara, and T. J. Strathmann. 2013. Continuous-flow photocatalytic treatment of pharmaceutical micropollutants: Activity, inhibition, and deactivation of $\mathrm{TiO}_{2}$ photocatalysts in wastewater effluent. Applied Catalysis B: Environmental 129, 1-12.

Chen, Y. and D. D. Dionysiou. 2008. Bimodal mesoporous $\mathrm{TiO}_{2}-\mathrm{P} 25$ composite thick films with high photocatalytic activity and improved structural integrity. Appl. Catal., B 80, 147-155.

Choi, H., E. Stathatos, and D. D. Dionysiou. 2006. Synthesis of nanocrystalline photocatalytic $\mathrm{TiO}_{2}$ thin films and particles using sol-gel method modified with nonionic surfactants. Thin Solid Films 510, 107-114.

de Lasa, H., B. Serrano-Rosales, and M. Salaices-Arredondo. 2005. In Photocatalytic Reaction Enginering. Springer. ISBN 0-387-23450-0.

de Ryck, A. and D. Quéré. 1998. Gravity and inertia effects in plate coating. Journal of Colloid and Interface Science 203(2), 278-285. 
Dijkstra, M. F. J., H. Buwalda, A. W. F. de Jong, A. Michorius, J. G. M. Winkelman, and A. A. C. M. Beenackers. 2001. Experimental comparison of three reactor designs for photocatalytic water purification. Chem. Eng. Sci. 56, 547-555.

Fabes, B. D., W. F. Doyle, B. J. J. Zelinski, L. A. Silverman, and D. R. Uhlmann. 1986. Strengthening of silica glass by gel-derived coatings. Journal of Non-Crystalline Solids 82(13), 349-355.

Gaya, U. I. and A. H. Abdullah. 2008. Heterogeneous photocatalytic degradation of organic contaminants over titanium dioxide: A review of fundamentals, progress and problems. J. Photochem. Photobiol., C 9, 1-12.

Greenspan, L. 1977. Humidity Fixed Points of Binary Saturated Aqueous Solutions. Journal of Research of the National Bureau of Standards - A. Physics and Chemistry 81A(1), 89 - 96.

Guillard, C., B. Beaugiraud, C. Dutriez, J. M. Herrmann, H. Jaffrezic, N. Jaffrezic-Renault, and M. Lacroix. 2002. Physicochemical properties and photocatalytic activities of $\mathrm{TiO}_{2}$-films prepared by sol-gel methods. Appl. Catal. , B 39, 331-342.

Herrmann, J. M. 2005. Heterogeneous photo-catalysis : state of the art and present applications. Topics in Catalysis 34 (1-4), 49-65.

Kete, M., E. Pavlica, F. Fresno, G. Bratina, and U. L. Stangar. 2014. Highly active photocatalytic coatings prepared by a low-temperature method. Environmental Science and Pollution Research 21(19), 11238-11249.

Meille, V., S. Pallier, G. V. Santa Cruz Bustamante, M. Roumanie, and J.P. Reymond. 2005. Deposition of layers on structured supports for the design of new catalytic reactors. Appl. Catal. A 286, 232-238.

Mills, A., J. Wang, and M. Crow. 2006. Photocatalytic oxidation of soot by $\mathrm{P} 25 \mathrm{TiO}_{2}$ films. Chemosphere 64, $1032-1035$. 
Natarajan, K., T. S. Natarajan, H. Bajaj, and R. J. Tayade. 2011. Photocatalytic reactor based on UV-LED/TiO 2 coated quartz tube for degradation of dyes. Chemical Engineering Journal 178, 40-49.

Ngamsinlapasathian, S., A. Kitiyanan, T. Fujieda, and S. Yoshikawa. 2006. Effects of substrates on Dye-Sensitized solar cell performance using nanocrystalline $\mathrm{TiO}_{2}$. ECS Transactions 1 (33), 7-15.

Rodriguez, P., V. Meille, S. Pallier, and M. A. Al Sawah. 2009. Deposition and characterisation of $\mathrm{TiO}_{2}$ coatings on various supports for structured (photo)catalytic reactors. Appl. Catal., A 360, 154-162.

Thevenet, F., O. Guaïtella, J. M. Herrmann, A. Rousseau, and C. Guillard. 2005. Photocatalytic degradation of acetylene over various titanium dioxide-based photocatalysts. Applied Catalysis B: Environmental 61(12), $58-68$.

Vezzoli, M., T. Farrell, A. Baker, S. Psaltis, W. N. Martens, and J. M. Bell. 2013. Optimal catalyst thickness in titanium dioxide fixed film reactors: Mathematical modelling and experimental validation. Chemical Engineering Journal 234, 57-65.

Yun, Y. J., J. S. Chung, S. Kim, S. H. Hahn, and E. J. Kim. 2004. Low-temperature coating of sol-gel anatase thin films. Mater. Lett. 58, 3703-3706.

Zhao, X., H. Lin, Y. Liu, X. Li, P. Yang, H. Chen, G. Wang, and J. Li. 2012. The effect of dispersion of TiO 2 nanoparticles on preparation of flexible dye-sensitized photoanodes. Science China Physics, Mechanics and Astronomy 55(7), 1203-1209. 


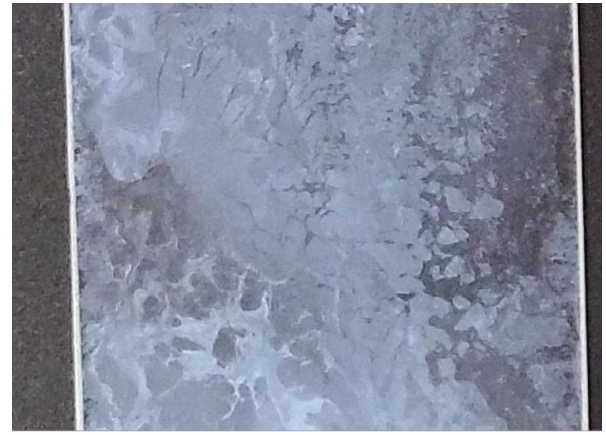

Figure 1: Example of one spray-coated glass slide 

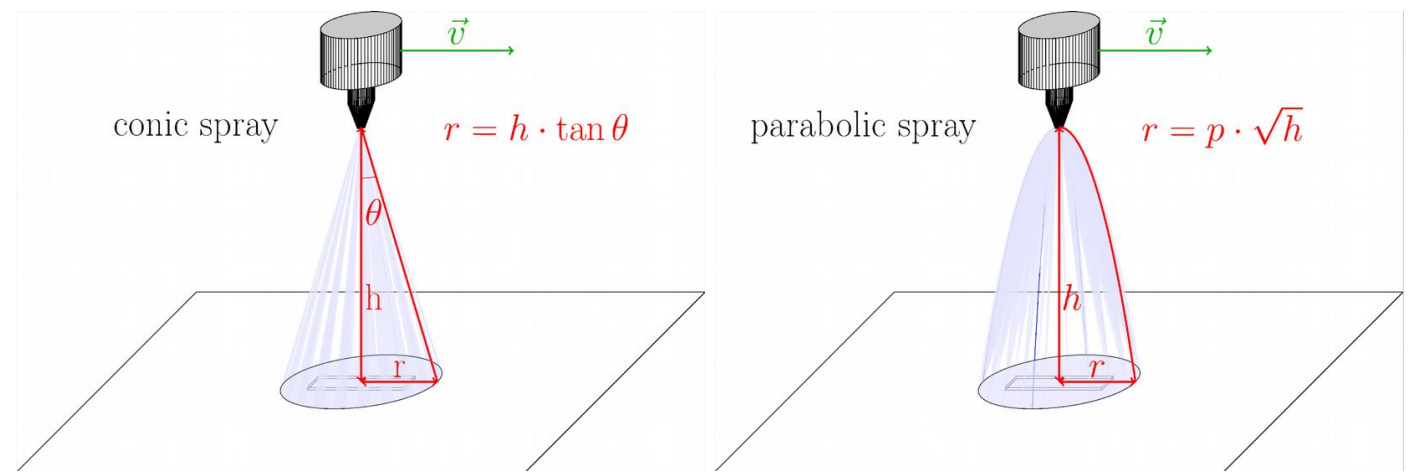

Figure 2: Shape of the spray for a) the conic model, b) the parabolic model 


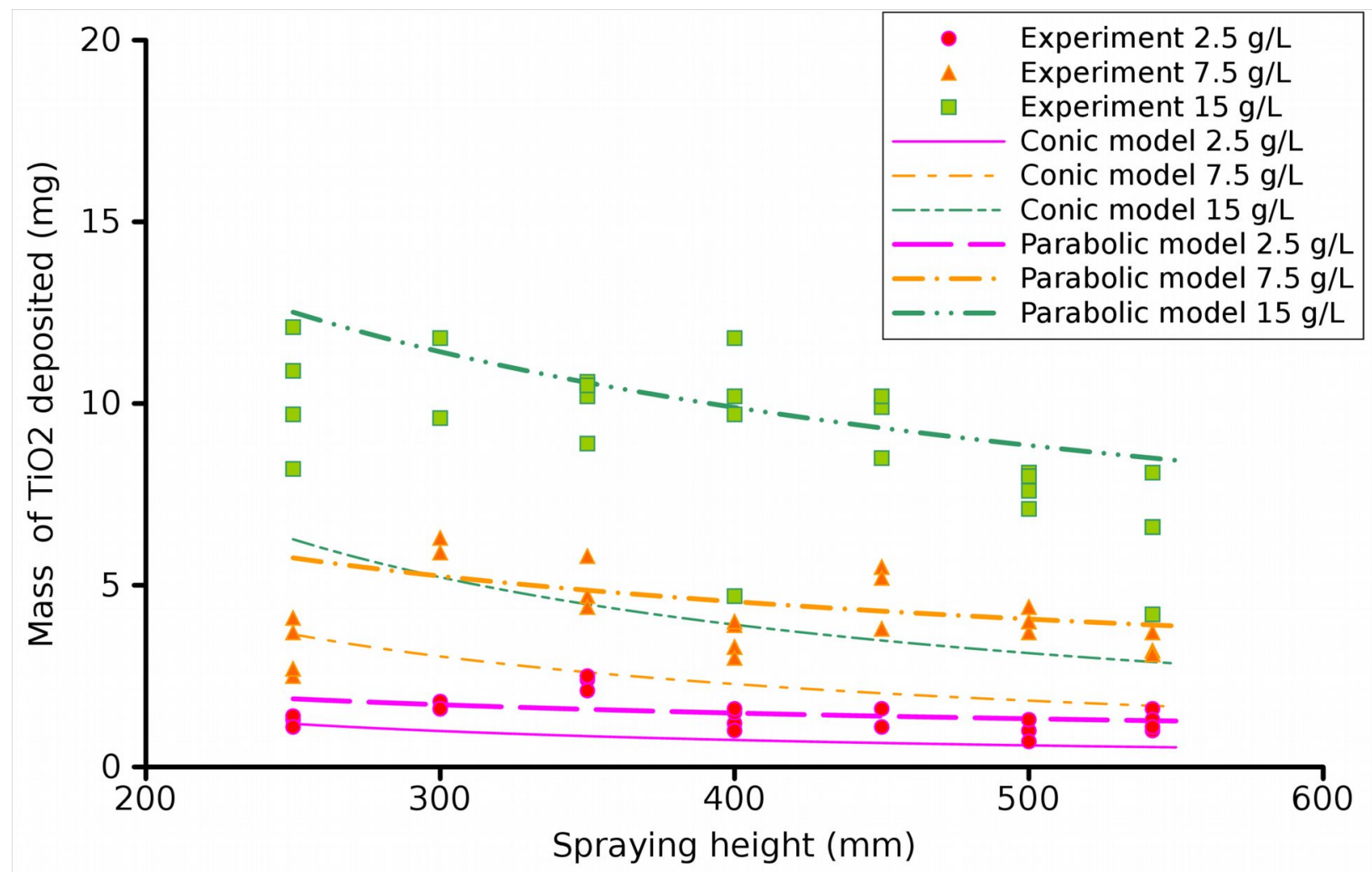

Figure 3: Spray-coating experiments at different $\mathrm{TiO}_{2}$ concentrations $($ Scanning speed $=16$ $\mathrm{mm} / \mathrm{s}$ ) - Comparison of parabolic and conic models 


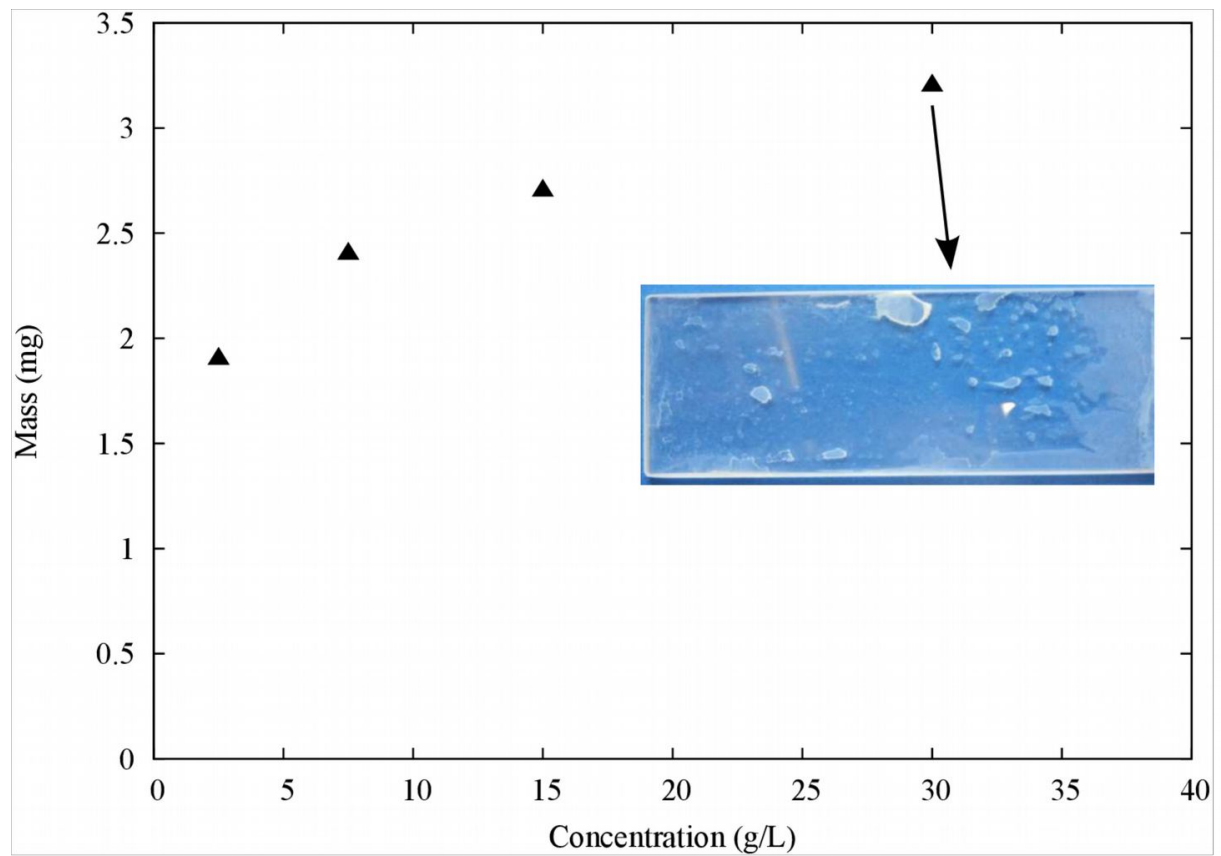

Figure 4: Effect of $\mathrm{TiO}_{2}$ loading in the suspension in the case of dip-coating method 

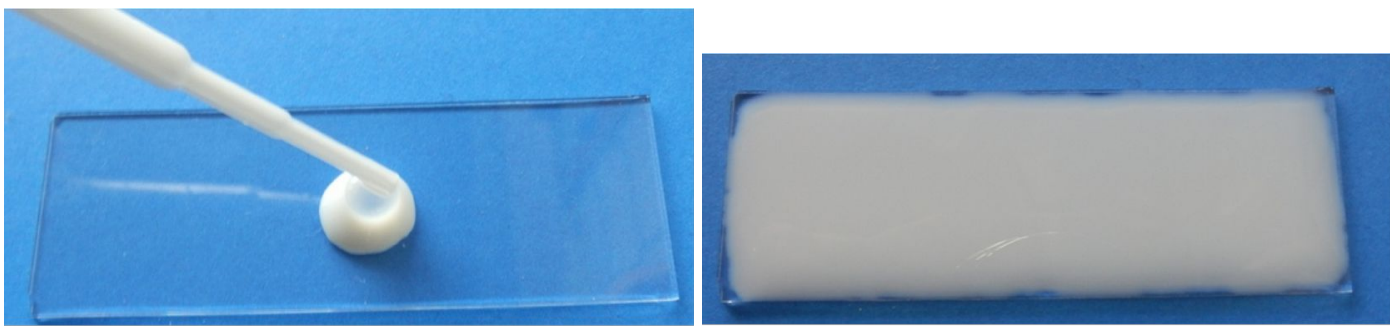

Figure 5: Drop-coating method and resulting liquid film 


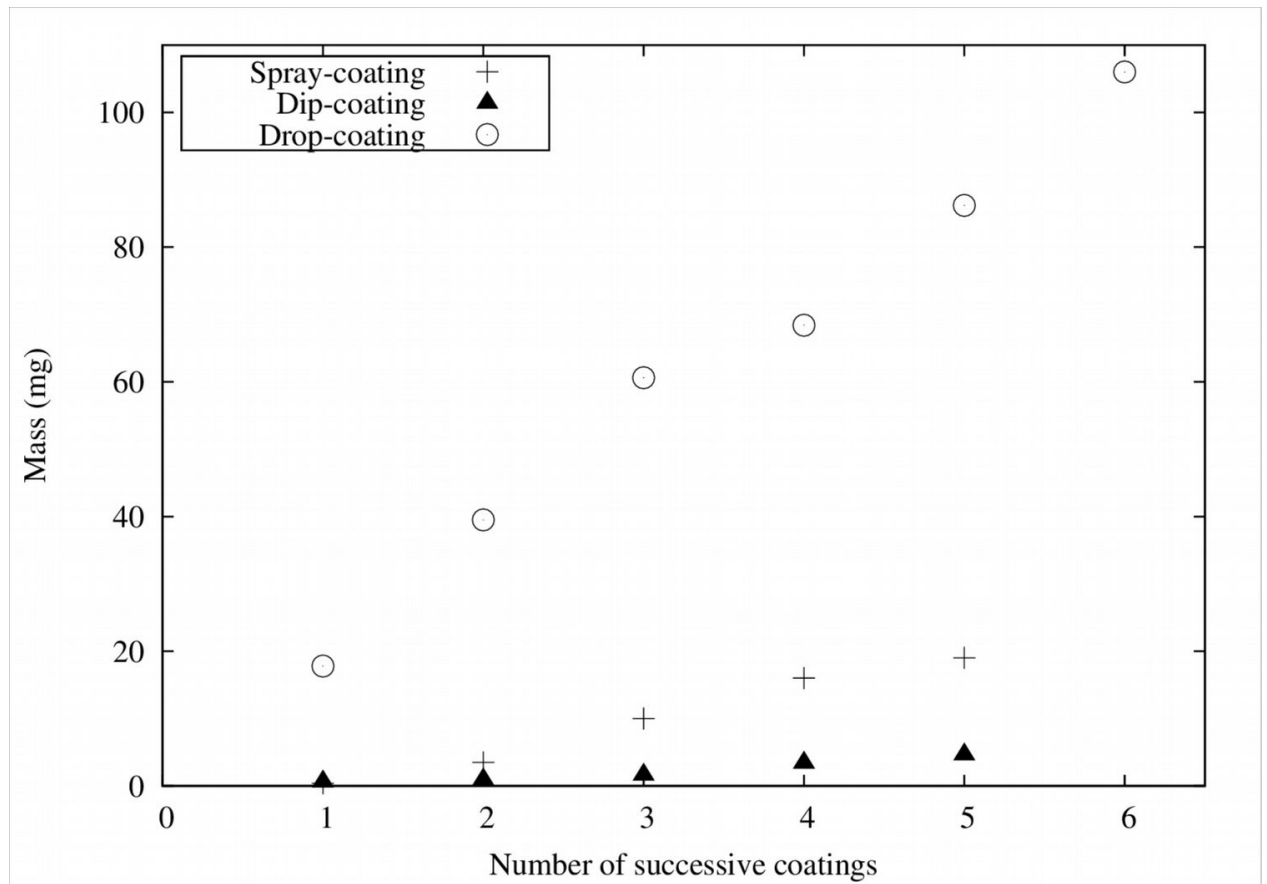

Figure 6: Mass of $\mathrm{TiO}_{2}$ layer obtained by successive coatings of a $7.5 \mathrm{~g} / \mathrm{L} \mathrm{TiO}{ }_{2}$ suspension by spray-, dip-, and drop-coating 


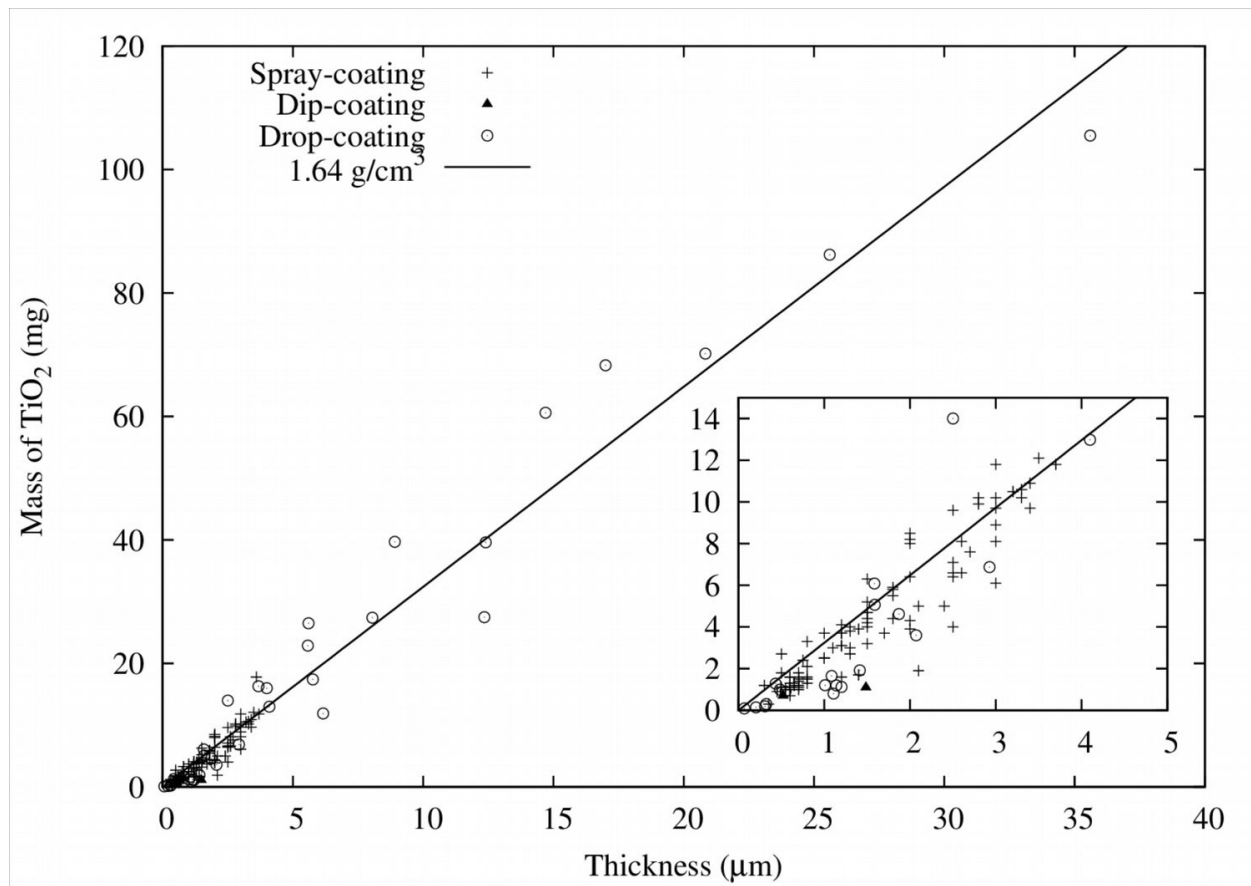

Figure 7: Mass vs. thickness for the three coating methods, with 1 to 6 successive layers 

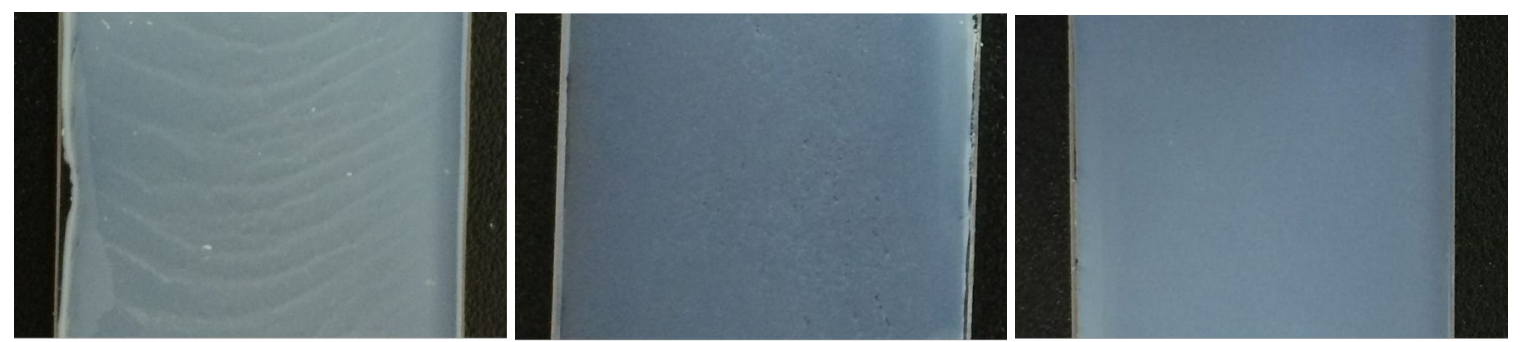

Figure 8: $\mathrm{TiO}_{2}$ drying in air of a drop-coated layer at 33\% RH (left), air at 55\% RH (middle) and air at $75 \% \mathrm{RH}($ right $)$ 


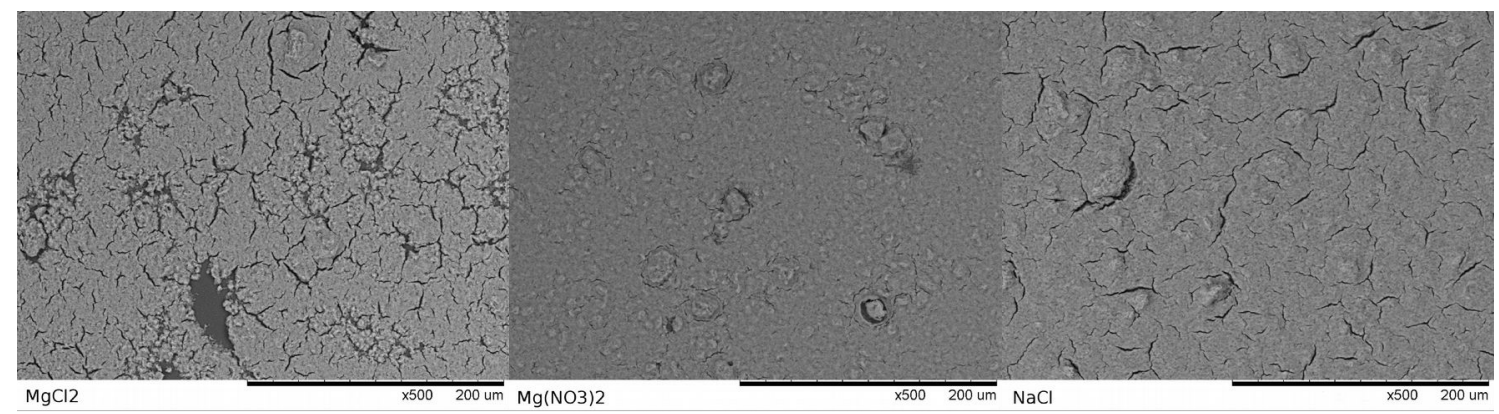

Figure 9: $\mathrm{SEM}$ pictures of $\mathrm{TiO}_{2}$ layer dried in air at 33\% RH (left), air at $55 \% \mathrm{RH}$ (middle) and air at $75 \% \mathrm{RH}($ right $)$ 


\begin{tabular}{ccccc} 
Glass treatment & Temperature & Additives & Contact angle & Adherence \\
\hline Acetone & RT & no & & - \\
Acetone & RT & PEG & & - \\
Acetone & RT & EG & $40^{\circ}$ & - \\
Acetone & RT & HCl & - \\
Acetone & RT & AA & - \\
Acetone & $40^{\circ} \mathrm{C}$ & no & - \\
Ethanol & RT & no & - \\
i-Propanol & RT & no & - \\
i-Propanol & $45^{\circ} \mathrm{C}$ & no & - \\
$\mathrm{NaOH}$ & $90^{\circ} \mathrm{C}$ & no & - \\
$\mathrm{NaOH}$ & $90^{\circ} \mathrm{C}$ & Darvan C & \\
$\mathrm{NaOH}$ & $90^{\circ} \mathrm{C}$ & Triton X100 & + \\
$\mathrm{NaOH}$ & $90^{\circ} \mathrm{C}$ & $\mathrm{HCl} \mathrm{1M}$ & $85^{\circ}$ & - \\
$\mathrm{NaOH}$ & $90^{\circ} \mathrm{C}$ & $\mathrm{PEG}$ & & + \\
$\mathrm{NaOH}$ & $90^{\circ} \mathrm{C}$ & $\mathrm{EG}$ & - \\
$\mathrm{NaOH}$ & $90^{\circ} \mathrm{C}$ & AA & & -
\end{tabular}

Table 1: Effect of glass pretreatments and additives on the qualitative adherence of the $\mathrm{TiO}_{2}$ layer 